\title{
Changes in the diagnosis and non-invasive treatment of chronic coronary syndromes in the last three European Society of Cardiology guidelines
}

\author{
Izabela Kozłowska', Przemysław Trzeciak², Mariusz Gąsior² \\ ${ }^{1}$ Clinical Department of Hematology and Cancer Prevention, Municipal Hospital, Chorzow, Poland \\ $23^{\text {rd }}$ Department of Cardiology, School of Medical Sciences in Zabrze, Medical University of Silesia in Katowice, Poland
}

Kardiochirurgia i Torakochirurgia Polska 2021; 18 (2): 105-110

\begin{abstract}
One of the most common forms of ischemic heart disease is chronic coronary syndromes (CCS), formerly known as stable coronary artery disease. During the last 15 years, the European Society of Cardiology has modified the guidelines for the diagnosis and treatment of CCS three times. The aim of this study was to analyze the changes in non-invasive diagnostics and pharmacotherapy of CCS that occurred in the last three guidelines. In non-invasive diagnostics, the most important change was reduction of the role of the electrocardiographic exercise test in favor of non-invasive stress imaging tests and computed tomography angiography. In pharmacotherapy, the role of $\beta$-blockers and calcium channel blockers has increased in controlling heart rate and symptoms. Intensive hypolipemic treatment for prevention of cardiovascular events and treatment with low doses of novel oral anticoagulants for those at high risk of cardiovascular events with sinus rhythm are among the recommendations.
\end{abstract}

Key words: chronic coronary syndromes, guidelines, European Society of Cardiology.

\section{Introduction}

Ischemic heart disease is a set of symptoms caused by the insufficient supply of oxygen and energy substrates in the heart muscle cells. In $80 \%$ of cases it is caused by the formation of atherosclerotic plaque. The atherosclerotic process begins as early as in the first decade of human life in an asymptomatic form, followed by a symptomatic acute form of acute coronary syndrome (ACS) or a chronic form of coronary artery disease (CAD) [1].

In August 2019, the European Society of Cardiology (ESC) released its guidelines for the management of patients with chronic coronary syndromes (CCS). The change of nomenclature was dictated by the fact that the atherosclerotic process is not stable but dynamic. Its natural course may be corrected by the modification of risk factors, pharmacotherapy, or revascularization. Therefore, CAD can manifest itself as CCS, or - in the case of a sudden event such as plaque erosion or rupture leading to myocardial ischemia - as ACS [2].

The new guidelines replaced the former recommendations released by the ESC in 2013 for the management of stable coronary artery disease (SCAD). Since 2006, when the first guidelines for the management of SCAD appeared, there have been changes not only in the nomenclature but, above all, in the area of diagnosis and treatment.
The aim of this study was to analyze the changes in the ESC recommendations for noninvasive diagnostics and pharmacotherapy of patients with SCAD and CCS over the past 14 years and their impact on the current management strategy in this group of patients.

\section{Non-invasive diagnostics}

The initial clinical evaluation of a patient with suspected or diagnosed CAD has not changed in the last three recommendations [2-4]. A resting electrocardiogram should be performed in every patient with suspected or diagnosed CCS, while a chest X-ray is recommended for selected patients (mainly those with atypical pain, those with suspected pulmonary disease, or those with suspected heart failure). Laboratory diagnostics has not changed significantly, either. A peripheral blood count, lipid profile, and creatinine tests should be performed for every patient with suspected or diagnosed CCS, while an evaluation of thyroid gland function is recommended for selected patients. For patients with suspected CAD, it is also necessary to perform a fasting glucose test and a glycated hemoglobin test $\left(\mathrm{HbA}_{1 \mathrm{c}}\right)$, and should the test results be inconclusive, an oral glucose load test should be performed [2-4].

In 2006 echocardiography was recommended mainly in patients after myocardial infarction (MI), patients with

Address for correspondence: Izabela Kozłowska MD, Clinical Department of Hematology and Cancer Prevention, Municipal Hospital, Chorzow, Poland, e-mail: ikozlowska777@gmail.com

Received: 14.02.2021, accepted: 27.04.2021. 
ECG abnormalities such as left bundle branch block (LBBB) or an abnormal Q wave, in patients with abnormalities in the physical examination suggestive of a structural heart disease such as valvular defects or hypertrophic cardiomyopathy, and in patients with symptoms of heart failure [3]. The authors of the 2013 guidelines recommended that echocardiography be performed in all patients with suspected CAD. This test serves risk stratification by allowing the assessment of left ventricular ejection fraction (LVEF) and the identification of segmental wall motion abnormalities that may suggest the presence of CAD. Furthermore, echocardiography allows the exclusion of other causes of angina [4]. Resting echocardiography was included in class I recommendations and credibility level B of the 2019 guidelines [2].

The past 14 years saw a marked change in the role of imaging studies in the diagnosis of CAD and the qualification for coronary angiography, including a decrease in the role of the exercise ECG. In 2006, exercise ECG was the primary diagnostic tool recommended for patients with symptoms of angina and an intermediate or high probability of CAD before testing (I B). For those unable to exercise or with existing contraindications to exercise, an imaging stress test or computed tomography angiography (CTA) provided an alternative [3].

After noninvasive testing, the authors of guidelines recommended risk stratification and classification of patients into one of three risk groups - low, intermediate, and high - with estimated annual cardiovascular mortality, respectively, at $<1 \%, 1-2 \%$ and $>2 \%$. Coronary angiography was recommended for the high-risk group and, optionally, based on the severity of symptoms and clinical evaluation, for the intermediate-risk group, while conservative treatment was recommended for the low-risk group [3].

The 2013 guidelines introduced a three-step decisionmaking process for the management of patients with suspected CAD, which included a pre-test probability (PTP) assessment, non-invasive diagnosis, and stratification of subsequent cardiovascular events. The PTP assessment was carried out in line with the estimates of CAD prevalence based on factors such as age, sex, and symptom characteristics (i.e. whether the chest pain is typical, atypical, or nonanginal). A low PTP (<15\%) invoked a recommendation of searching for another cause of symptoms, an intermediate PTP (15-85\%) entailed a recommendation of performing noninvasive diagnostic tests, and a high-risk group (PTP > 85\%) was recommended to be diagnosed with $\mathrm{CAD}$ and referred for coronary angiography [4].

Exercise ECG was recommended as the initial test in patients with an intermediate probability of CAD (I B), although stress test imaging had a similar or better sensitivity and specificity. A non-invasive stress test was recommended as the initial test primarily in patients with abnormalities in their electrocardiograms that prevented the interpretation of the recording during the exercise, as well as in patients with an already established diagnosis of CAD, after previous coronary interventions [4].
The latest 2019 ESC guidelines have significantly altered the previous PTP values. According to a new recommendation, the selection of a method of diagnosing CAD should include, in addition to PTP, the so-called modifiers consisting of, among other things, the results of certain laboratory tests (including a lipid profile, fasting blood glucose, $\mathrm{HbA}_{1 \mathrm{c}}$ ), 12-lead ECG, echocardiography, or computed tomography (CT) coronary artery calcification index. Based on PTP and the modifiers, a clinical probability of CAD is established, which determines further management. In high-risk patients with typical angina symptoms, refractory to treatment, occurring at a low exercise intensity, and with a high probability of CAD, coronarography is recommended. In lowand intermediate-risk patients, non-invasive stress test imaging or CTA is recommended [2]. In this group of patients, exercise ECG has so far been the initial diagnostic test for $C A D$, unless baseline electrocardiographic changes precluded its interpretation or the patient was unable to perform it for other reasons [3, 4]. The 2019 guidelines reduced the role of ST ECG to class IIb. The authors of the guidelines recommend that this group of patients be diagnosed using noninvasive and stress imaging modalities, such as CTA, stress magnetic resonance imaging $(\mathrm{MRI})$, stress echocardiography, single photon emission tomography, positron emission tomography (PET), and contrast echocardiography [2].

The choice of the type of a noninvasive test should result from an assessment of the clinical probability of CAD (CTA is preferred for low-risk CAD), factors that may influence the outcome, local knowledge, and the availability of the test. The ST is currently recommended mainly to determine exercise capacity and blood pressure (BP) amplitude, to reveal arrhythmias, and to establish risk in selected patients or when functional testing is not available. In symptomatic patients, for whom CAD cannot be ruled out by a clinical assessment, stress imaging or CTA is recommended [2] (Table I).

\section{Non-pharmacological treatment}

The 2013 and 2019 guidelines focus a lot on the role of lifestyle changes and non-pharmacological treatment. Recommendations on smoking prohibition, diet, and nutrition have not changed significantly over the years. Although all recommendations emphasized the role of physical activity, the most recent guidelines recommend 30-60 minutes of moderate physical activity on most days of the week. The authors of the guidelines emphasize that even irregular activity is beneficial [2]. The doses of acceptable alcohol intake have changed. The 2013 guidelines recommended limiting alcoholic beverages intake to 2 units per day (20 g of alcohol per day) in men and 1 unit per day (10 g of alcohol per day) in non-pregnant women [4]. The authors of the most recent recommendations reduced the allowable amount of alcohol to $100 \mathrm{~g} /$ week or $15 \mathrm{~g} /$ day [2].

\section{Pharmacological treatment}

The 2006 guidelines introduced two goals of pharmacological treatment. The first one included improving the 
Table I. Changes in diagnostic methods in three consecutive ESC guidelines

\begin{tabular}{|c|c|c|c|}
\hline $\begin{array}{l}\text { Diagnostic } \\
\text { methods }\end{array}$ & 2006 & 2013 & 2019 \\
\hline $\begin{array}{l}\text { Laboratory } \\
\text { tests }\end{array}$ & $\begin{array}{l}\text { - In all patients: peripheral blood count (I C), } \\
\text { creatinine (I C), fasting glucose (I B), lipid } \\
\text { profile (I B) } \\
\text { - OGTT (Ila B) } \\
\text { - Indicators of myocardial damage with } \\
\text { signs of instability (I A) } \\
\text { - Evaluation of thyroid function with clinical } \\
\text { justification (I C) }\end{array}$ & $\begin{array}{l}\text { - In all patients: peripheral blood } \\
\text { count (I B), creatinine (I B), fasting } \\
\text { glucose, } \mathrm{HbA}_{1 \mathrm{c}}(\mathrm{I} \mathrm{B}) \text {, lipid profile (I C) } \\
\text { - hsTNT at symptoms of instability (I A) } \\
\text { - Evaluation of thyroid function with } \\
\text { clinical justification (I C) }\end{array}$ & $\begin{array}{l}\text { - In all patients: peripheral blood } \\
\text { count (I B), creatinine (I A), fasting } \\
\text { glucose, } \mathrm{HbA}_{1 \mathrm{c}} \text { (I B), lipid profile (I A) } \\
\text { - hsTNT at symptoms of instability (I A) } \\
\text { - Evaluation of thyroid function with } \\
\text { clinical justification (I C) }\end{array}$ \\
\hline ECG & - In all patients (I C) & - in all patients (I C) & - In all patients (I C) \\
\hline ECG Holter & $\begin{array}{l}\text { - Angina with suspected arrhythmia (I B) } \\
\text { - Suspected angina pectoris (Ila C) }\end{array}$ & $\begin{array}{l}\text { - Stable CAD and suspected } \\
\text { arrhythmia (I C) } \\
\text { - Suspected angina pectoris (IIa C) }\end{array}$ & $\begin{array}{l}\text { - Chest pain with suspected } \\
\text { arrhythmia (I C) } \\
\text { - Suspected angina pectoris (Ila C) }\end{array}$ \\
\hline Chest X-ray & $\begin{array}{l}\text { - Suspected HF (I B) } \\
\text { - Suspected pulmonary disease (I C) }\end{array}$ & $\begin{array}{l}\text { - Suspected HF (Ila C) } \\
\text { - Suspected pulmonary disease (I C) }\end{array}$ & - Suspected HF or lung disease (I C) \\
\hline Echo & $\begin{array}{l}\text { - Suspected valvular defect, HCM, HF (I B) } \\
\text { - After MI (I B) } \\
\text { - ECG changes: LBBB, LAH, path Q wave (I C) }\end{array}$ & - In all patients (I B) & - In all patients (I B) \\
\hline Exercise ECG & $\begin{array}{l}\text { - Symptoms and an intermediate or high } \\
\text { probability of CAD (I B) }\end{array}$ & $\begin{array}{l}\text { - Angina and an intermediate } \\
\text { probability of CAD (I B) }\end{array}$ & $\begin{array}{l}\text { - For an assessment of exercise } \\
\text { tolerance, symptoms, arrhythmia, } \\
\text { RR response (I C) } \\
\text { - As an alternative to non-invasive } \\
\text { or invasive stress testing when } \\
\text { unavailable (IIb B) }\end{array}$ \\
\hline $\begin{array}{l}\text { Non-invasive } \\
\text { imaging } \\
\text { stress tests } \\
\text { or CTA }\end{array}$ & $\begin{array}{l}\text { Stress tests using echocardiography/ } \\
\text { perfusion scintigraphy: } \\
\text { - ECG changes preventing the interpretation } \\
\text { of ExT (I B) } \\
\text { - An inconclusive ExT result and a low } \\
\text { probability of CAD (I B) } \\
\text { - As an alternative to ExT if available (Ila B) } \\
\text { - After revascularization (Ila B) } \\
\text { - Functional evaluation of intermediate to } \\
\text { advanced lesions on coronary angiography } \\
\text { (Ila C) } \\
\text { CTA: } \\
\text { - A low probability of CAD, inconclusive ExT } \\
\text { or imaging findings (IIb C) }\end{array}$ & $\begin{array}{l}\text { Stress echocardiography, CMR, } \\
\text { SPECT or PET, or CTA: } \\
\text {-As an initial test if available (I B) } \\
\text { - ECG changes preventing the } \\
\text { interpretation of ExT (I B) } \\
\text { - After revascularization (IIa B) } \\
\text { - A functional evaluation of } \\
\text { intermediate coronary lesions (IIla B) }\end{array}$ & $\begin{array}{l}\text { Stress echocardiography, CMR, } \\
\text { SPECT or PET, or CTA: } \\
\text { - As an initial investigation in } \\
\text { patients with CAD symptoms (I B) } \\
\text { - the choice of technique dependent } \\
\text { on the clinical probability of CAD } \\
\text { and test availability of (I C) }\end{array}$ \\
\hline
\end{tabular}

CAD - coronary artery disease, CMR - cardiac magnetic resonance, CTA - computed tomography angiography, ECG - electrocardiogram, ExT - electrocardiographic exercise test, HbA1C - glycated hemoglobin, HCM - hypertrophic cardiomyopathy, HF - heart failure, hsTNT - high-sensitivity troponin, LAH - left anterior bundle branch block, LBBB - left bundle branch block, MI - myocardial infarction, OGTT - oral glucose tolerance test, PET - positron emission tomography, RR - blood pressure, SPECT - single photon emission tomography, Echo - echocardiography.

prognosis, while the second one included reducing the symptoms and/or ischemia [3]. To improve the prognosis, the importance of angiotensin converting enzyme (ACE) inhibitors has clearly increased, as confirmed by the randomized clinical trials EUROPA (EURopean trial On reduction of cardiac events with Perindopril in stable coronary artery disease Investigators) and HOPE (Heart Outcomes Prevention Evaluation) [5, 6]. ACE inhibitors in patients with additional clinical indications such as hypertension, heart failure, left ventricular dysfunction, post-myocardial infarction status, or diabetes mellitus were promoted to the highest class of recommendations (I A). In all patients with angina and diagnosed CAD, ACE inhibitors were recommended in class Ila B. The first-line therapy to improve the prognosis included, in addition to ACE inhibitors, antiplatelet agents (acetylsalicylic acid (ASA) and/or alternatively clopidogrel Ila $B$ ) and statins (I A). To improve the prognosis, $\beta$-blockers were mainly recommended for patients after myocardial infarction or with concomitant heart failure (I A) [3].

For symptom relief and the reduction of ischemia, the authors recommended short-acting nitroglycerin ( $\mathrm{B}$ ) and $\beta$-blockers (I A) or, in case of their intolerance, calcium channel blockers (CCBs) (I A). The 2006 guidelines were quite groundbreaking because of the introduction of new drugs intended to reduce clinical symptoms: nicorandil as a potassium channel opener (I C), ivabradine as an If ion current inhibitor acting at the level of sinus node cells (Ila B), and trimetazidine as an anti-anginal metabolic agent (IIb B) [3].

The main pharmacotherapy goals of the 2013 guidelines included symptom relief and prevention of cardiovascular events [4]. To manage angina, in addition to short-acting nitrates (I B), $\beta$-blockers and/or CCBs were recommended as the first-line therapy to control heart rate frequency and clinical symptoms (I A). The addition of long-acting nitrates, 
Changes in the diagnosis and non-invasive treatment of chronic coronary syndromes in the last three European Society of Cardiology guidelines

Table II. Changes in diagnostic methods in three consecutive ESC guidelines

\begin{tabular}{|c|c|c|c|}
\hline $\begin{array}{l}\text { Pharmaco- } \\
\text { therapy }\end{array}$ & 2006 & 2013 & 2019 \\
\hline \multicolumn{4}{|c|}{ Recommendations for preventing cardiac events } \\
\hline ACE-I, ARB & $\begin{array}{l}\text { - In patients with angina and } \\
\text { diagnosed CAD (IIa B) } \\
\text { - In patients with burdens of HA, } \\
\text { HF, post-MI status with LV } \\
\text { dysfunction, DM (I A) }\end{array}$ & $\begin{array}{l}\text { - In patients with burdens (e.g. HF, } \\
\text { HA, or DM) (I A) }\end{array}$ & $\begin{array}{l}\text { - In patients with burdens (e.g. HF, HA, or } \\
\text { DM) (I A) } \\
\text { - In patients at a very high risk of CV events } \\
\text { (IIa A) }\end{array}$ \\
\hline ASA & $\begin{array}{l}\text { - In all patients without } \\
\text { contraindications (I A) }\end{array}$ & $\begin{array}{l}\text { - ASA at a dose of } 75-150 \mathrm{mg} / \text { day in } \\
\text { all patients with stable CAD (I A) }\end{array}$ & $\begin{array}{l}\text { - ASA at } 75-100 \mathrm{mg} / \text { day in patients after MI } \\
\text { or with a history of revascularization (I A) } \\
\text { - In patients without MI or a history of } \\
\text { revascularization, ASA at } 75-100 \mathrm{mg} / \text { day if } \\
\text { CAD is diagnosed on imaging studies (IIb C) }\end{array}$ \\
\hline $\begin{array}{l}\text { Other anti- } \\
\text { coagulants }\end{array}$ & $\begin{array}{l}\text { - Clopidogrel for contraindications } \\
\text { for ASA (Ila B) }\end{array}$ & $\begin{array}{l}\text { - Clopidogrel for contraindications } \\
\text { for ASA (I B) }\end{array}$ & $\begin{array}{l}\text { - Clopidogrel for contraindications for ASA (I B) } \\
\text { - Adding a second thrombolytic drug } \\
\text { (clopidogrel/ prasugrel/rivaroxaban/ } \\
\text { ticagrelor) to ASA in patients at a high } \\
\text { ischemic risk and the absence of a high } \\
\text { bleeding risk (Ila A) } \\
\text { - The above option in patients with an } \\
\text { intermediate risk of ischemia and the } \\
\text { absence of a high bleeding risk (IIb A) }\end{array}$ \\
\hline $\begin{array}{l}\text { Statins } \\
\text { and other } \\
\text { hypolipidemic } \\
\text { drugs }\end{array}$ & $\begin{array}{l}\text { - Statins in all patients with } \\
\text { coronary artery disease } \\
\text { (I A) (treatment goal } \\
\text { LDL-C }<2.5 \text { mmol/l ( } 96 \mathrm{mg} / \mathrm{dl} \text { ) } \\
\text { - Fibrates in patients with low } \\
\text { HDL-C and high TG, with DM } \\
\text { and/or MS (Ilb B) }\end{array}$ & $\begin{array}{l}\text { - Statins in all patients with coronary } \\
\text { artery disease }(\mathrm{A}) \text { (treatment goal } \\
\mathrm{LDL}-\mathrm{C}<1.8 \mathrm{mmol} / \mathrm{l}(70 \mathrm{mg} / \mathrm{dl}) \text { or } \\
\text { a reduction by }>50 \%)\end{array}$ & $\begin{array}{l}\text { - Statins in all patients with CCS (I A) (in } \\
\text { patients with a very high risk of CV events, } \\
\text { the treatment goal of LDL-C < } 55 \mathrm{mg} / \mathrm{dl} \text { or } \\
\text { a reduction > 50\% of the baseline level of } \\
1.8-3.5 \mathrm{mmol} / \mathrm{l}(70-135 \mathrm{mg} / \mathrm{dl} \text { ) } \\
\text { - Adding ezetimibe if the treatment goal } \\
\text { of statin therapy alone at the maximum } \\
\text { tolerated dose is not achieved (I B) } \\
\text { - Adding a PCSK9 inhibitor if target lipid } \\
\text { concentrations are not achieved in very } \\
\text { high-risk patients on the maximum } \\
\text { tolerated dose of statins in combination } \\
\text { with ezetimibe (I A) }\end{array}$ \\
\hline
\end{tabular}

\section{Recommendations on the use of anti-ischemic drugs}

\begin{tabular}{|c|c|c|c|}
\hline$\beta$-Blockers & - In patients after MI or with HF (I A) & \multirow{2}{*}{$\begin{array}{l}\text { - BB and/or CCB as first-line drugs } \\
\text { for HR and symptom control (I A) }\end{array}$} & \multirow{2}{*}{$\begin{array}{l}\text { - BB and/or CCB as first-line drugs to control } \\
\text { HR and symptoms (I A) } \\
\text { - Association of BB and DHP-CCB as the first- } \\
\text { line therapy (Ila B) }\end{array}$} \\
\hline CCB & $\begin{array}{l}\text { - CCB in case of lack of effect of BB } \\
\text { or their intolerance (I A) } \\
\text { - Combination treatment of DHP } \\
\text { derivative with BB in patients } \\
\text { with an insufficient effect after BB } \\
\text { in monotherapy (I B }\end{array}$ & & \\
\hline $\begin{array}{l}\text { Short-acting } \\
\text { nitrates }\end{array}$ & $\begin{array}{l}\text { - Nitroglycerin to relieve symptoms } \\
\text { and reduce ischemia (I B) }\end{array}$ & $\begin{array}{l}\text { - To relieve symptoms and reduce } \\
\text { ischemia (I B) }\end{array}$ & $\begin{array}{l}\text { - For an immediate relief of angina } \\
\text { symptoms (I B) }\end{array}$ \\
\hline $\begin{array}{l}\text { Long-acting } \\
\text { nitrates }\end{array}$ & $\begin{array}{l}\text { - In monotherapy for BB intolerance } \\
\text { (I C) }\end{array}$ & \multirow{2}{*}{$\begin{array}{l}\text { - Second-line addition of long-acting } \\
\text { nitrates, ivabradine, nicorandil, or } \\
\text { ranolazine, depending on HR, BP, } \\
\text { and tolerability (Ila B) }\end{array}$} & $\begin{array}{l}\text { - First-line therapy, in case of intolerance or } \\
\text { insufficient effect of BB and/or CCB (Ila B) }\end{array}$ \\
\hline Other drugs & $\begin{array}{l}\text { - Nicorandil in monotherapy for BB } \\
\text { intolerance (I C) } \\
\text { - Ivabradine as an alternative in BB } \\
\text { intolerance (Ila B) }\end{array}$ & & \multirow{2}{*}{$\begin{array}{l}\text { - Nicorandil, ranolazine, ivabradine, or } \\
\text { trimetazidine in the second-line setting } \\
\text { to reduce angina symptoms and improve } \\
\text { exercise tolerance if BB, CCB, and long- } \\
\text { acting nitrates are contraindicated, poorly } \\
\text { tolerated, or insufficient to control angina } \\
\text { (Ila B) }\end{array}$} \\
\hline $\begin{array}{l}\text { Metabolic } \\
\text { drugs }\end{array}$ & $\begin{array}{l}\text { - Trimetazidine added to therapy to } \\
\text { reduce ischemic symptoms or as } \\
\text { a substitute if the primary therapy } \\
\text { is intolerable (Ilb B) }\end{array}$ & $\begin{array}{l}\text { - Trimetazidine as part of the second- } \\
\text { line therapy (IIb B) }\end{array}$ & \\
\hline
\end{tabular}

ASA - acetylsalicylic acid, ACE-I - angiotensin-converting enzyme inhibitor, ARB - angiotensin receptor blocker, BB - $\beta$-blocker, BP - blood pressure, CAD - coronary artery disease, CCB - calcium channel blocker, CCS - chronic coronary syndrome, CV - cardiovascular, DHP - dihydropyridine, DM - diabetes mellitus, HA - hypertension, HDL-C - high-density lipoprotein fraction cholesterol, HR - heart rate, LDL-C - low-density lipoprotein fraction cholesterol, LV - left ventricle, MI - myocardial infarction, MS - metabolic syndrome, PCSK9 - proprotein convertase subtilisin/kexin type 9, TG - triglycerides. 
ivabradine, nicorandil, or ranolazine, depending on heart rate frequency, blood pressure, and tolerability (Ila $B$ ), or trimetazidine (IIb B) was recommended as the second-line therapy drug [4].

For the prevention of cardiovascular events, the 2013 guidelines were not significantly different from the 2006 recommendations that included improving the prognosis. All patients with stable CAD were recommended to be administered a low dose of ASA (I A) or, if intolerable, alternatively clopidogrel (I B), statin (I A), and an ACE inhibitor or angiotensin receptor antagonist, if other conditions such as heart failure, hypertension, or diabetes (I A) were present [4].

The latest 2019 guidelines introduced significant changes not only in nomenclature, but also in pharmacotherapy. The overarching goals of treatment remained unchanged: the relief of angina symptoms and the prevention of cardiovascular events [2]. Short-acting nitrates (I B) have remained recommended for the relief of coronary symptoms in the presence of exertional angina. The new recommendations strengthened the importance of $\beta$-blockers and CCBs as first-line drugs in controlling heart rate frequency and symptoms (I A). If the use of a $\beta$-blocker or CCB has not provided sufficient control of angina symptoms, the guideline authors recommend considering a combination of a $\beta$-blocker and a dihydropyridine CCB (IIa C) as the first-line treatment (Ila $B$ ). The guidelines recommend that the second-line treatment includes the use of long-acting nitrates (Ila B), nicorandil, ranolazine, ivabradine, and trimetazidine in patients for whom the treatment with $\beta$-blockers, CCBs, and long-acting nitrates is contraindicated, poorly tolerated, or insufficient to control angina symptoms (Ila B) [2].

Multiple changes have been introduced in the recommendations for the prevention of cardiovascular events. As a matter of long-term secondary prevention in patients at a high risk of ischemic events and without a high risk of bleeding, the guidelines recommended considering adding a second anticoagulant to ASA (75-100 mg/day), notwithstanding the concomitant sinus rhythm (Ila A). A high risk of ischemic events was defined as disseminated multivessel $C A D$, with at least one of the following conditions: diabetes mellitus requiring pharmacological treatment, recurrent myocardial infarction, peripheral arteriosclerosis, or chronic kidney disease with a filtration rate of $15-59 \mathrm{ml}$ $\min / 1.73 \mathrm{~m}^{2}$ [2]. Dual antithrombotic treatment should include a second antiplatelet drug (clopidogrel $75 \mathrm{mg} /$ day, prasugrel 5 or $10 \mathrm{mg} /$ day, or ticagrelor $60 \mathrm{mg}$ twice daily) or rivaroxaban administered at a dose of $2.5 \mathrm{mg}$ twice daily [2].

In patients with non-valvular atrial fibrillation and indications for anticoagulation therapy, non-vitamin $\mathrm{K}$ antagonist oral anticoagulants (NOACs) are recommended preferentially to vitamin $\mathrm{K}$ antagonists (VKAs) (I A). In patients who tolerate NOACs, apixaban $5 \mathrm{mg}$ twice daily, dabigatran $150 \mathrm{mg}$ twice daily, or rivaroxaban $20 \mathrm{mg}$ once daily is recommended instead of VKAs in combination with an antiplatelet therapy. If the high risk of bleeding outweighs the risk of stent thrombosis or an ischemic stroke during a single or dual antiplatelet therapy, it is recommended to consider rivaroxaban $15 \mathrm{mg}$ once daily or dabigatran $110 \mathrm{mg}$ twice daily (Ila B). A proton pump inhibitor is recommended for patients receiving ASA, a dual antiplatelet therapy, or anticoagulant monotherapy, who are at a high risk of gastrointestinal bleeding (I A). The recent guidelines have introduced significant changes in LDL cholesterol targets for patients at a very high cardiovascular risk, with LDL cholesterol targets below $55 \mathrm{mg} / \mathrm{dl}$. In addition to lifestyle changes, an intensive hypolipidemic treatment should be introduced to achieve the recommended values. Statins (I A) are recommended for all patients with CCS. A novelty in the recent guidelines involves the addition of ezetimibe to the maximum tolerated statin dose (I B), should the target lipid concentrations not be achieved. If the target lipid concentrations are still not achieved in very high-risk patients using the maximum tolerated dose of statins in combination with ezetimibe, the addition of a proprotein convertase subtilisin/kexin type 9 (PCSK9) inhibitor is recommended (I A) [2].

The authors of the guidelines point to new groups of hypoglycemic drugs recommended for patients with diabetes and a concomitant CCS. Sodium-glucose cotransporter 2 inhibitors (empagliflozin, canagliflozin, or dapagliflozin) and glucagon-like peptide 1 receptor agonists (liraglutide or semaglutide) are recommended (I A) in patients with cardiovascular disease and diabetes [2] (Table II).

\section{Conclusions}

Over the past 15 years, three updates of the guidelines for the management of stable coronary artery disease (currently chronic coronary syndromes) have been published. The rapid progress of medicine has caused significant changes in the diagnosis and non-invasive treatment. The reduction of clinical symptoms and the prevention of cardiovascular incidents remain the most important goals of treatment.

\section{Disclosure}

The authors report no conflict of interest.

\section{References}

1. Kosmicki MA Ischemic heart disease in Poland and the world - a fully unresolved problem. Fact-Based Cardiology 2010; 1: 35-48.

2. Knuuti J, Wijns W, Saraste A, Capodanno D, Barbato E, Funck-Brentano C, Prescott E, Storey RF, Deaton C, Cuisset T, Agewall S, Dickstein K, Edvardsen T, Escaned J, Gersh BJ, Svitil P, Gilard M, Hasdai D, Hatala R, Mahfoud F, Masip J, Muneretto C, Valgimigli M, Achenbach S, Bax JJ; ESC Scientific Document Group2019 ESC Guidelines for the diagnosis and management of chronic coronary syndromes: The Task Force for the diagnosis and management of chronic coronary syndromes of the European Society of Cardiology (ESC). Eur Heart J 2020; 41: 407-77.

3. Fox K, Garcia MA, Ardissino D, Buszman P, Camici PG, Crea F, Daly C, De Backer G, Hjemdahl P, Lopez-Sendon J, Marco J Morais J, Pepper J, Sechtem U, Simoons M, Thygesen K, Priori SG, Blanc JJ, Budaj A, Camm J, Dean V, Deckers J, Dickstein K, Lekakis J, McGregor K, Metra M, Morais J, Osterspey A, Tamargo J, Zamorano JL, Task Force on the Management of Stable Angina Pectoris of the European Society of Cardiology; ESC Committee for Practice Guidelines (CPG). Guidelines on the management of stable angina pectoris: executive summary: The Task Force on the Management of Stable Angina Pectoris of the European Society of Cardiology. Eur Heart J 2006; 27: 1341-81. 
4. Montalescot G, Sechtem U, Achenbach S, Andreotti F, Arden C, Budaj A, Bugiardini R, Crea F, Cuisset T, Di Mario C, Ferreira JR, Gersh BJ, Gitt AK, Hulot JS, Marx N, Opie LH, Pfisterer M, Prescott E, Ruschitzka F, Sabaté M, Senior R, Taggart DP, van der Wall EE, Vrints CJM, ESC Committee for Practice Guidelines; Zamorano JL, Achenbach S, Baumgartner H, Bax JJ, Bueno H, Dean V, Deaton C, Erol C, Fagard R, Ferrari R, Hasdai D, Hoes AW, Kirchhof P, Knuuti J, Kolh P, Lancellotti P, Linhart A, Nihoyannopoulos P, Piepoli MF, Ponikowski P, Sirnes PA, Tamargo JL, Tendera M, Torbicki A, Wijns W, Windecker S, Document Reviewers; Knuuti J, Valgimigli M, Bueno H, Claeys MJ, DonnerBanzhoff N, Erol C, Frank H, Funck-Brentano C, Gaemperli O, GonzalezJuanatey JR, Hamilos M, Hasdai D, Husted S, James SK, Kervinen K, Kolh P,
Kristensen SD, Lancellotti P, Maggioni AP, Piepoli MF, Pries AR, Romeo F, Rydén L, Simoons ML, Sirnes PA, Steg PG, Timmis A, Wijns W, Windecker S, Yildirir A, Zamorano JL. 2013 ESC guidelines on the management of stable coronary artery disease: the Task Force on the management of stable coronary artery disease of the European Society of Cardiology. Eur Heart J 2013; 34: 2949-3003.

5. Fox KM Efficacy of perindopril in reduction of cardiovascular events among patients with stable coronary artery disease: randomised, double-blind, placebo-controlled, multicentre trial (the EUROPA study). Lancet 2003; 362: 782-8. 6. Sleight P. The HOPE Study (Heart Outcomes Prevention Evaluation). J Renin Angiotensin Aldosterone Syst 2000; 1: 18-20. 